\title{
Periodic Behavior of Deep Sea Current in the Hatoma Knoll Hydrothermal System
}

\author{
Yasuo Furushima and Hiroyuki Yamamoto
}

\begin{abstract}
Time series physical properties of water column were measured at the Hatoma Knoll hydrothermal field on the Okinawa Trough, using a multi-layered Acoustic Doppler Current Profiler (ADCP). We aimed (1) to provide a deep-sea current data within a small and complicated geographical feature of a caldera and (2) to show the possibility of hydrothermal plume observation by ADCP during the measurement in April 2004 and May 2005 cruises. The deep-sea current data were recovered at the depths between seafloor and 40-m or 60-m-layers above the seafloor. Moreover, acoustic reflection signals were sometimes observed up to 120 -m layer above the seafloor due to the trail of hydrothermal plumes. A power spectrum density analysis by fast Fourier transform (FFT) showed the dominant time cycle of the horizontal current velocity, which corresponded to tidal periodicity over an approximate 12-hours period, at each layer. Residual currents, which play an important role in material transport, tended to northwest direction and suggested that most of material might keep retaining within the caldera. The causes of the measurement result of the flow which appeared into a pulse form may indicate fluctuation of the blowout of hydrothermal water. The verification of the fluid mechanism by the numerical model in the local field such as the caldera will be necessary in the future.
\end{abstract}

Keywords

ADCP • Backscattering • Deep sea current • Hatoma Knoll

Y. Furushima $(\bowtie)$

Institute of Biogeosciences, Japan Agency for Marine-Earth Science and Technology (JAMSTEC), 2-15 Natsushima-Cho, Yokosuka, Kanagawa 237-0061, Japan

e-mail: furus@jamstec.go.jp

H. Yamamoto

Institute of Biogeosciences, Japan Agency for Marine-Earth Science and Technology (JAMSTEC), 2-15 Natsushima-Cho, Yokosuka, Kanagawa 237-0061, Japan

Submarine Resource Research Project, Japan Agency for Marine-Earth Science and Technology (JAMSTEC), 2-15 Natsushima-Cho,

Yokosuka, Kanagawa 237-0061, Japan

\subsection{Introduction}

Hydrothermal fluids spouting from a deep-sea hydrothermal vent forms hydrothermal plumes by mixing with surrounding seawater. Hydrothermal plume has various physical and chemical signatures, e.g. higher temperatures than surrounding seawater, high chemical components from hydrothermal fluids, and high particle concentration from hydrothermal fluid chemicals. Deep-sea current around the hydrothermal vent field provides a turbulent environment, related to effects such as complex geographical topography and the hydrothermal venting flows. To estimate a heat and chemical flux from a hydrothermal vent, it is necessary to investigate a hydrothermal plume (Baker et al. 2001). Especially for the time series observation, an acoustic 
instrumentation is useful tool to determine physical environmental factors such as current and water temperature.

It is also important to understand the deep-sea current around the hydrothermal vent, because it gives us to understand how eggs and larvae at the deep sea are distributed and transported among the hydrothermal vent fields. Based on deep-sea current measurements, Thomson et al. (2003) indicated that tidal and wind-generated currents were dominant at the Endeavour segment in the Juan de Fuca ridge, and the hydrothermal plumes tended to stay within the valley. This result suggests that an inhibition of oscillatory currents in the rift valleys of mid-ocean ridges shield larvae from cross-axis dispersion in the deep ocean.

Fujioka et al. (1997) have measured deep-sea currents and water temperature for 1 year using a mooring observatory settled on the TAG hydrothermal mound in the MidAtlantic Ridge. They found that $12.42 \mathrm{~h}$ cycle corresponded with a lunar semi-diurnal periodicity, known as M2 tidal constituent, was dominated in the TAG site flow, and synchronization of the fluctuation cycle of temperature and pressure with this tidal periodicity. Such a water flow pattern of deep-sea zone strongly influences plume spouting out of hydrothermal vent, larval dispersion and planktonic life.

Mitsuzawa (2003) carried out a towing survey of the deepsea current using JAMSTEC/Deep Tow system equipped with down-looking ADCP in hydrothermal region in the Southern Mariana Trough. In the Mid Okinawa Trough hydrothermal region, they also carried out the survey of the deep-sea current using the Shinkai 2000 and the ROV Dolphin $3 \mathrm{~K}$ equipped with ADCP. Because an acoustic backscatter of ADCP was too weak and heaving effect of the vessel affected the survey in the Mariana Trough, current measurement of deep-sea zone was difficult by conventional method.

Current profile and occasional turbulent is considered as effective factors for chemicals dispersion from the hydrothermal vent, and transportation of eggs and larvae from hydrothermal community. However, few studies have been conducted based on in situ measurements of the physical environmental condition on hydrothermal vent field. In this study, we determined current profiles at the Hatoma Knoll hydrothermal field to characterize the physical environment. The purpose of this study is to reveal the profile of the deepsea current, and examined an acoustic detection of hydrothermal plume by ADCP.

\subsection{Field Observation and Method}

\subsubsection{Observation Site}

Hatoma Knoll has a caldera rim that is open to south, and is located $50 \mathrm{~km}$ northwest of Ishigaki Island in Okinawa prefecture, Japan (Ishibashi et al. Chap. 29). Many hydrothermal vents, including some bubbling vents, have been found from the central to the western slope of Hatoma Knoll Caldera. Hatoma Knoll has a height difference of approximately $600 \mathrm{~m}$ and most of the hydrothermal vents locate at about 1,500-m in water depth (Fig. 50.1). The total hydrothermal area is estimated to be about $16,800 \mathrm{~m}^{2}$ (Watanabe 2001). Physical environments were observed for a few weeks using the ADCP at Hatoma Knoll (Fig. 50.1) in April 2004 and May 2005.

\subsubsection{Measuring Apparatus}

ADCP (Teledyne RD Instruments Workhorse Sentinel, $300 \mathrm{kHz}$ : Fig. 50.1) is an apparatus used to measure multilayered ocean currents. Using the Doppler effect of ultrasonic wave emitted from four transducers, ADCP provides current direction and velocity, water temperature, depth (pressure) and intensities of reflection signals. The ADCP was placed at almost the same place in the both cruises, located at the west of the caldera apertural area of Hatoma Knoll (Fig. 50.1). Installation and recovery of the ADCP were performed using a remotely operated vehicle HYPERDOLPHIN (JAMSTEC). Deep-sea current was measured using the ADCP from 16 to 24 April 2004, and from 30 April to 13 May 2005. The ADCP measurement was used the following condition; $10 \mathrm{~min}$ interval of sounding, and current profiling range constituted by 60 layers with $2 \mathrm{~m}$ thickness. The deepest layer in water column was located $4 \mathrm{~m}$ above ADCP. The current profiling by the ADCP reached to $120 \mathrm{~m}$ upper layer from the seafloor.

\subsection{Results}

\subsubsection{In Situ Observation in Hatoma Knoll}

Figures 50.2 and 50.3 show the results of current measurement by the ADCP in the apertural area of Hatoma Knoll in April 2004 and May 2005. In both figures, the following are shown: (a) current velocity $(\mathrm{mm} / \mathrm{s})$; (b) east-west component current velocity $(\mathrm{mm} / \mathrm{s})$; (c) north-south component current velocity $(\mathrm{mm} / \mathrm{s})$; (d) vertical component current velocity $(\mathrm{mm} / \mathrm{s})$; (e) water temperature $\left({ }^{\circ} \mathrm{C}\right.$, blue line); (f) depth ( $\mathrm{m}$, green line). And the red bar graph $(\mathrm{g})$ indicates the number of layers that were measured by the ADCP.

The current velocity was approximately $10 \mathrm{~cm} / \mathrm{s}$ for the east-west and north-south components, and a periodic fluctuation was observed in synchronization with a shift of water depth. There was a rise and fall in the depth fluctuation twice a day, which was synchronized with the tidal fluctuation. In the measurements in 2004, the water temperature fluctuation exhibited a slight diurnal rise and fall. 

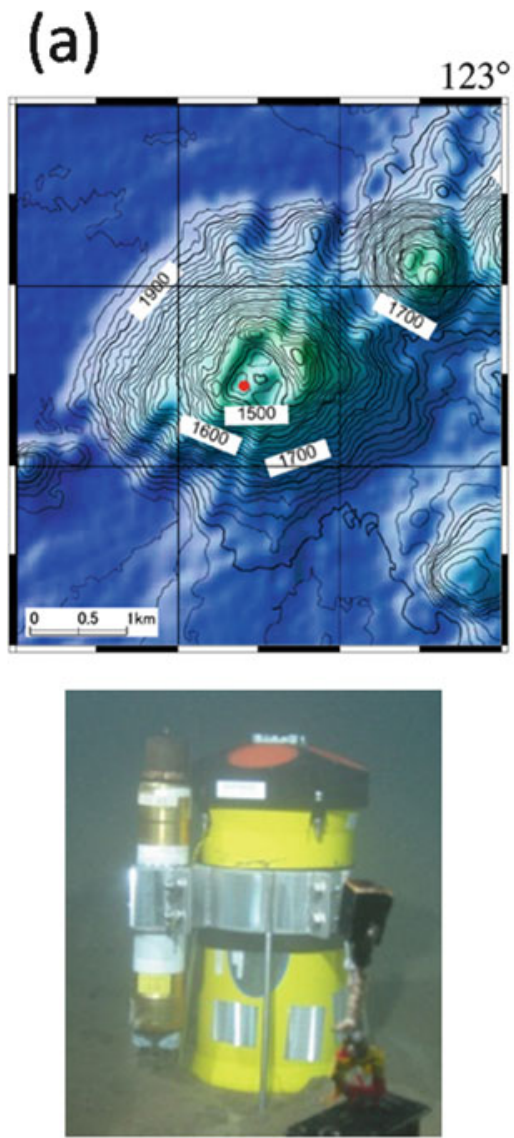

(c)

Fig. 50.1 Schematic view of the Hatoma Knoll in Okinawa Trough. (a) Bathymetric chart in the Hatoma knoll. (b) Locations of ADCP measurements in 2004 (red square) and 2005 (blue square) cruise and

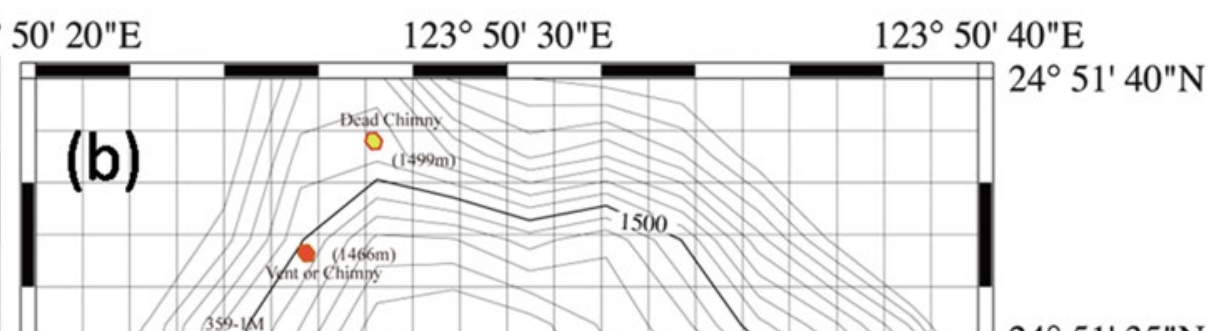

$24^{\circ} 51^{\prime} 35^{\prime \prime} \mathrm{N}$
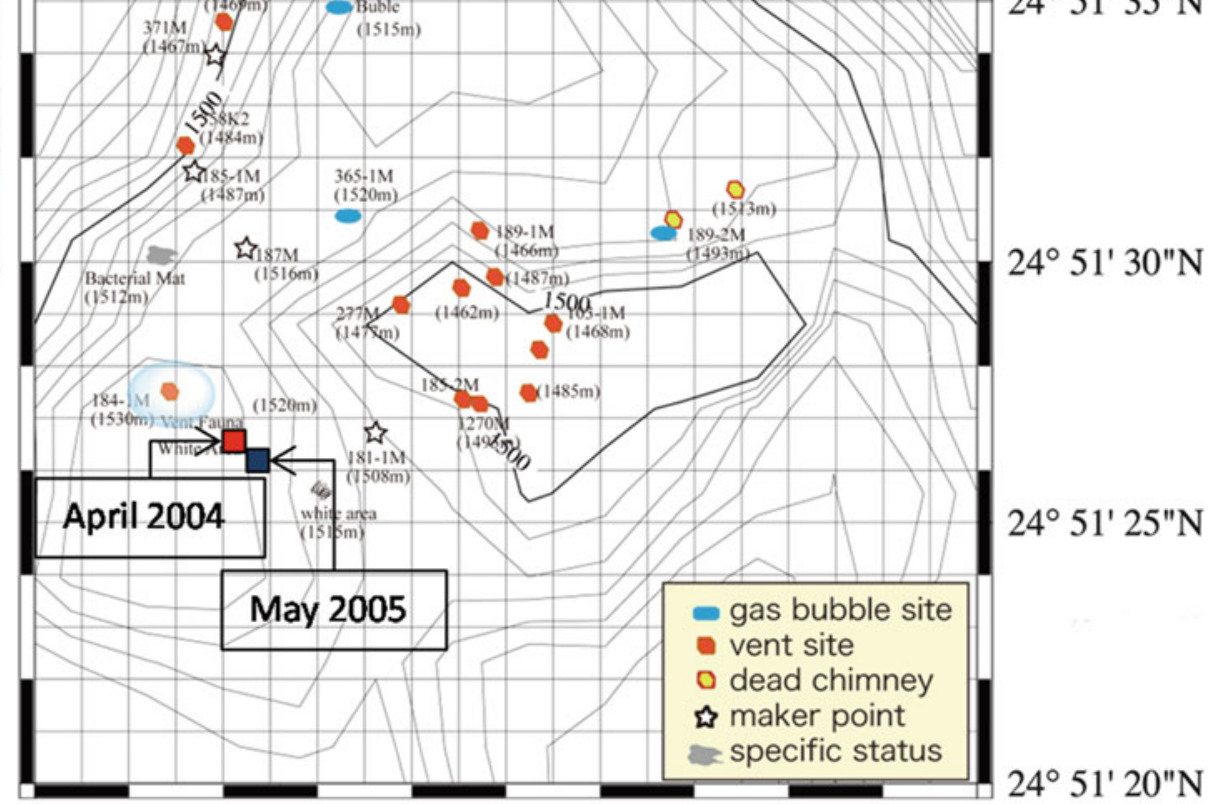

distribution of hydrothermal vents in the Hatoma Knoll Caldera. (c) Picture of the ADCP placed on the seafloor in 2004

It is important to stress that the current measurement using the ADCP was not provided in all layers of the area of observation during both years. The measurement result for the consecutive flow was either provided from the bottom to the 20th layer (in 2004 it was provided from the bottom to approximately the $44 \mathrm{~m}$ upper layer) or from the bottom to the 30th layer (in 2005 it was provided from the bottom to approximately the $64 \mathrm{~m}$ upper layer). However, there was a time zone when it was possible to measure using a pulse form to around the upper layer, in almost all the layers of the area of observation this was possible in a time zone when the tide shifted from ebb tide to high tide, for a time period of approximately $3 \mathrm{~h}$. The depth fluctuation was compared with the possible number of layers included in the measurement (Figs. 50.2 and 50.3, green line and red bar graph).

Variation of the horizontal current velocity of layers 1, 10, 20, 25, and 30 in 2005 is shown in Fig. 50.4. Variation of the vertical flows the layers are shown in Fig. 50.5. The horizontal current (Fig. 50.4) of each layer during high tide showed a direction to a northward. In contrast, during the ebb tide, southward-current was predominant. These fluctuations were similar to the variation in the semidiurnal tidal current in the shallow water region in the Taketomi Submarine Hot Springs of the southern part of Yaeyama Archipelago (http://coral.godac.jp/md/jam_sekisei/4-1a. $\mathrm{html})$. The horizontal current velocity showed slightly faster in the shallower layers below 20-m above the seafloor. We observed the weak and downward current velocities for the vertical axis.

\subsubsection{Characteristics of the Dominant Time Cycle at Hatoma Knoll}

We analyzed the data set appeared in Fig. 50.4 by a power spectrum in order to examine the dominant time cycle of the horizontal current velocity at each layer (Fig. 50.6). Spectrum density of the current velocity of east-west component 

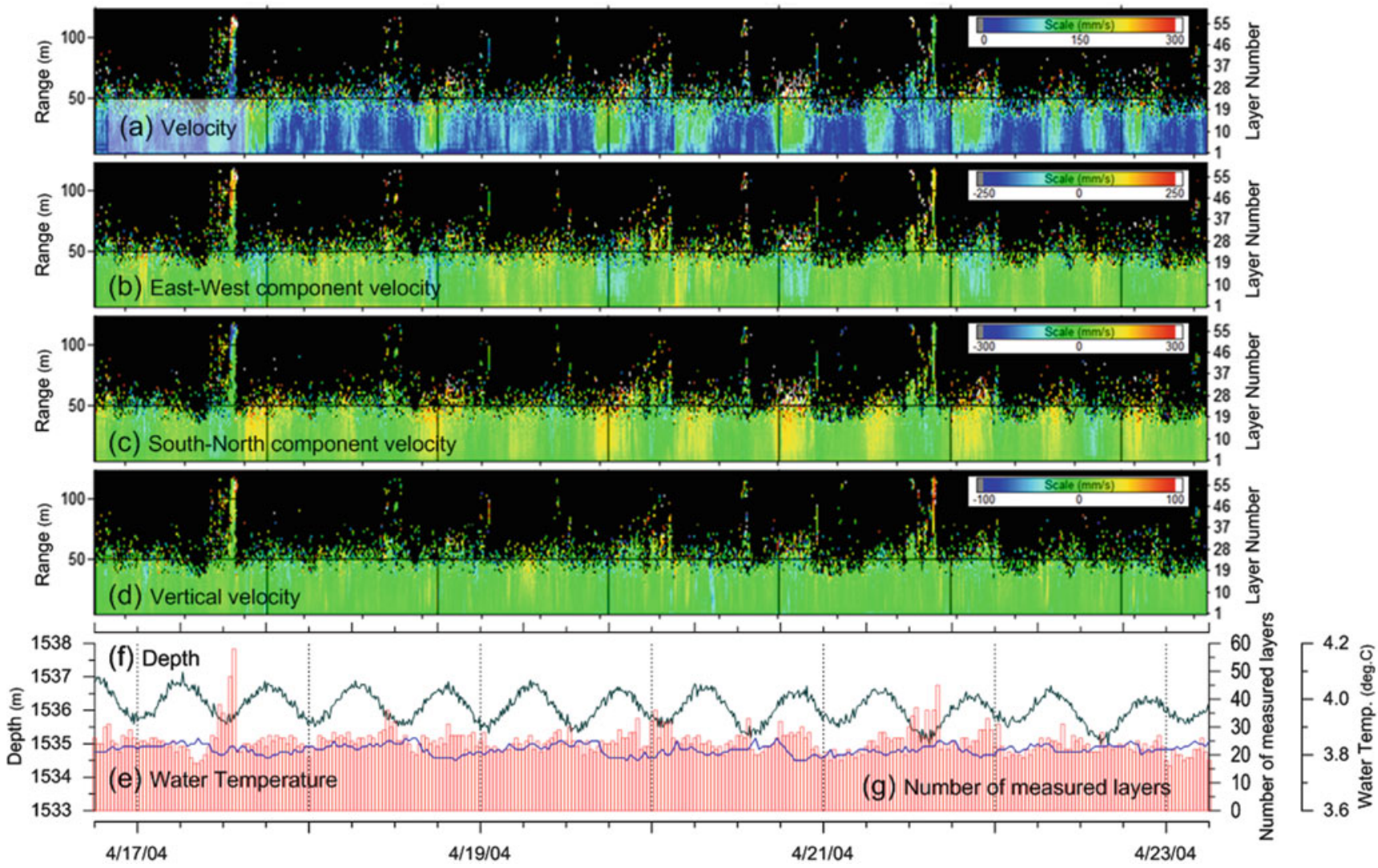

Fig. 50.2 Results of current measurement using the ADCP in April 2004. (a) Current velocity (mm/s). (b) Current velocity of East-west component $(\mathrm{mm} / \mathrm{s})$. (c) Current velocity of the north-south component $(\mathrm{mm} / \mathrm{s})$. (d) Current velocity of the vertical component $(\mathrm{mm} / \mathrm{s})$. (e) Water temperature $\left({ }^{\circ} \mathrm{C}\right)$ : blue line. (f) Depth $(\mathrm{m})$ : green line. $(\mathrm{g})$

Number of measured layers: red bar chart. The right axis shows the layer number. The left-sided axis shows the height from the approximate sea bottom. The thickness is set to $2 \mathrm{~m}$, and the flow was measured from the bottom through 60 layers

and north-south component in layers 1 and 20 was calculated using FFT analysis. As a result, we found a dominant time cycle of semidiurnal with approximately $12 \mathrm{~h}$ periodicity. The semidiurnal current at deep sea has been observed at the mid Atlantic Ridge (Fujioka and Mitsuzawa 2001) and around the seafloor off the Oahu Island, Hawaii (Aucan et al. 2006).

\subsection{Discussion}

\subsubsection{Tidal Residual Current in the Caldera Structures of Hatoma Knoll}

The tidal current in shallow coastal regions is caused by a horizontal repetitive motion of seawater with the rise and fall of the sea's surface due to the tide, and consists of a periodic component in synchrony with the tide (Pond and Pickard 1983). The water particles transported by a tidal current do not return to their original position, due to density stratification and bottom topography, even after completion of an entire period. This current is called the tidal residual current. The tidal residual current (residual current) plays an important role in long-term material transport. In the deep-sea hydrothermal area, the deep-sea residual tidal currents also plays an important role to supply chemical components such as trace minerals originated from hydrothermal fluids and organic materials produced in the plumes (Sunamura and Yanagawa, Chap. 3), as well as to disperse the eggs and larvae of chemosynthetic communities (Vrijenhoek 2010).

Constraint factors for distribution of the hydrothermal plume were buoyancy, chemical composition, the deep-sea current and the seafloor topography. Consequently, the deepsea current is important for transportation of the plume, chemical compounds, eggs, and larvae of the deep-sea organisms in the hydrothermal vent field. The fluctuation of the residual current at Hatoma Knoll is shown in Fig. 50.7. The residual current was calculated using the 25 -h moving average (eliminated in tidal periodicity) of the current measurement results. In the lower layers (from the bottom to the $60 \mathrm{~m}$ above the seafloor) of the Hatoma Knoll apertural area, the northward flow was dominant. This indicates that the 

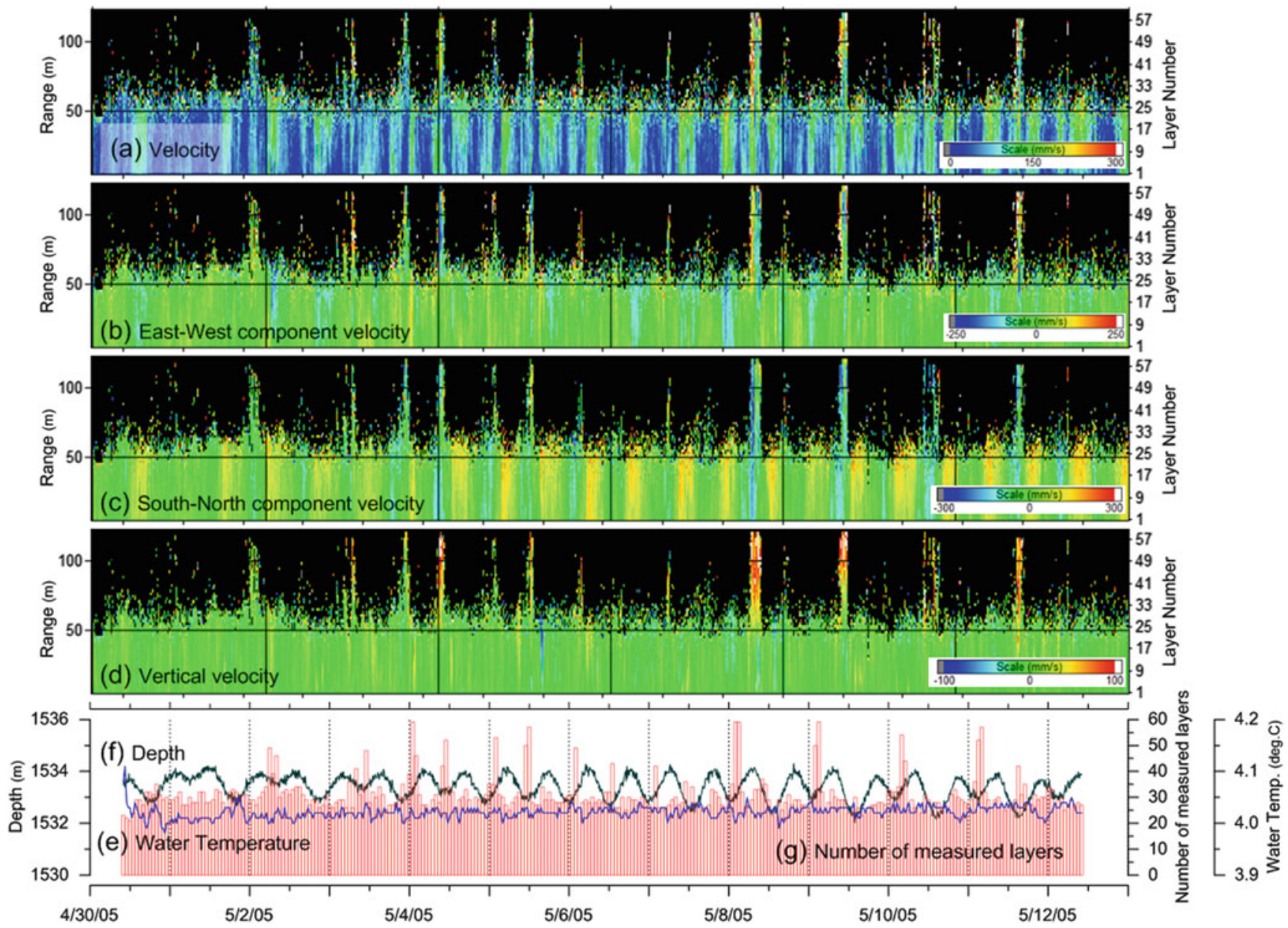

Fig. 50.3 Current measurement results using the ADCP in May 2005. (a) Current velocity of East-west component $(\mathrm{mm} / \mathrm{s})$. (b) Current velocity of the north-south component $(\mathrm{mm} / \mathrm{s})$. (c) Current velocity of the vertical component $(\mathrm{mm} / \mathrm{s})$. (d) Current velocity $(\mathrm{mm} / \mathrm{s})$. (e) Water temperature $\left({ }^{\circ} \mathrm{C}\right)$ : blue line. $(\mathbf{f})$ Depth $(\mathrm{m})$ : green line. $(\mathbf{g})$

material transport from caldera to outside will be weak in the lower layer (approximately 50-m above the seafloor) of the apertural area of the south side in the Hatoma knoll. In other words, outside seawater flows in from apertural area lower layer of the south side in the knoll, and it is considered that the seawater in the caldera flows out other region, such as top of the caldera and the apertural area upper layer. We also calculated the vertical current velocity (Fig. 50.8), and found that the downward flow was prominent in the layers from the sea bottom to the $50 \mathrm{~m}$ above the seafloor. Because Hatoma Knoll has a closed topography with the same water-depth of the top of caldera rim, there is a possibility that materials (chemical compounds, eggs and larvae) are resident within the caldera. In addition, a fluctuation period of 2-3 days was found in the fluctuation of the residual current in Fig. 50.7. The reason for such a fluctuation period is not known, but we speculate that a variation in the hydrothermal venting period may be occurring, thereby varying the volume of the
Number of measured layers: red bar chart. The right axis shows the layer number. The left-sided axis shows the height from the approximate sea bottom. The thickness was set to $2 \mathrm{~m}$, and the flow was measured from the bottom through 60 layers

hydrothermal water. Therefore a long and continuous measurement of hydrothermal venting fluids and the numerical modeling will be needed to know the main component of the residual current in the Hatoma knoll.

\subsubsection{Behavior of the Backscattering}

The ADCP measures the current velocity and direction by detection of reflecting sound wave signals. The ADCP transmits high frequency sound waves $(300 \mathrm{kHz})$ from four transducers (Fig. 50.9), and determining the Doppler frequency shift of return-reflected signal from particles in the seawater (Emery and Thomson 2004). Through the ADCP measurements, we can obtain the backscatter signal intensity as well as velocity. Figure 50.10 shows temporal variation of backscatter signal intensity from May 7, 2005 at 18:00 and May 9, 2005 at 18:00, when pulsatile current was observed. 


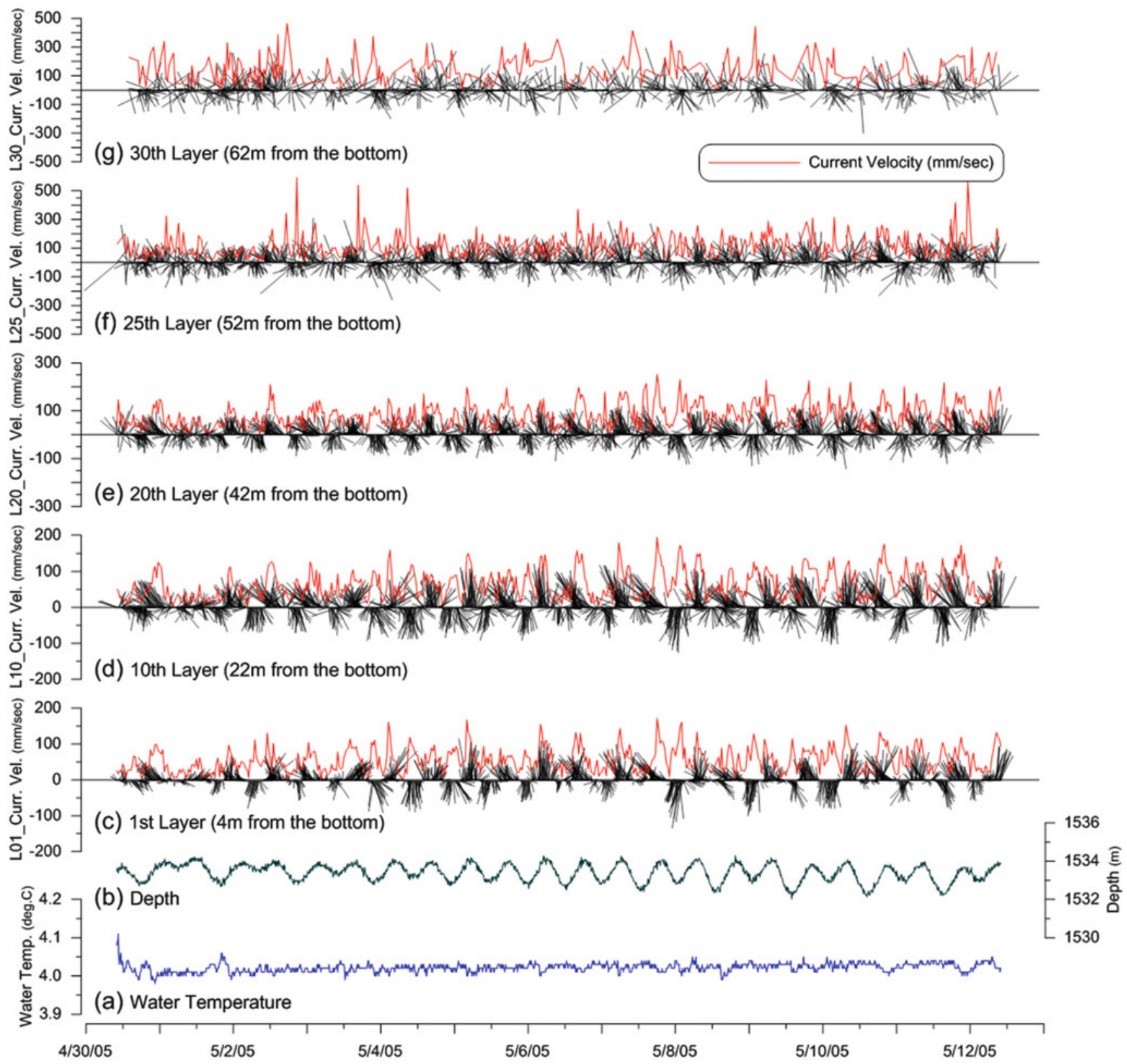

Fig. 50.4 Fluctuation of current velocity, current direction, water temperature, and depth, at the sea bottom. (a) Water Temperature $\left({ }^{\circ} \mathrm{C}\right)$. (b) Depth (m). (c) Fluctuation of the current velocity at layer 1 (4 $\mathrm{m}$ from the bottom). (d) Fluctuation of the current velocity at layer 10 (22 $\mathrm{m}$ from the bottom). (e) Fluctuation of the current velocity at layer 20 (42 $\mathrm{m}$ from the bottom). (f) Fluctuation of the current velocity at layer $25(52 \mathrm{~m}$ from the bottom). (g) Fluctuation of the current

velocity at layer 30 (62 $\mathrm{m}$ from the bottom). Current velocity unit is $\mathrm{mm} / \mathrm{s}$. The red line in the figure shows current velocity. The black line shows the current velocity. The plus value of the current velocity expresses the northward and eastward flow, respectively. In the case of a negative value, the current velocity represents a southward and westward flow

We found sharp and high backscatter intensity signals through the water column from 23:00 on May 7 to 4:00 May 8 and from 23:00 on May 8 to 4:00 on May 9. Four transducers of the ADCP were placed on a circle as shown in Fig. 50.9. In Beam 4 at the east side of the apparatus, high backscattering intensity was observed at around $100 \mathrm{~m}$ from the bottom at about 0:00 on May 8. The high backscattering was observed at $75 \mathrm{~m}$ from sea bottom in Beam 2 located in the south side of Beam4 at about 2:00 on May 8. In Beam3, we were not able to identify the distribution of remarkable high backscattering. However, in Beam1, the high backscattering was detected at $50 \mathrm{~m}$ from the bottom at about 2:00 on May 8, and at $75 \mathrm{~m}$ around 3:00. We consider that the behavior of the high backscattering on ADCP data indicates 


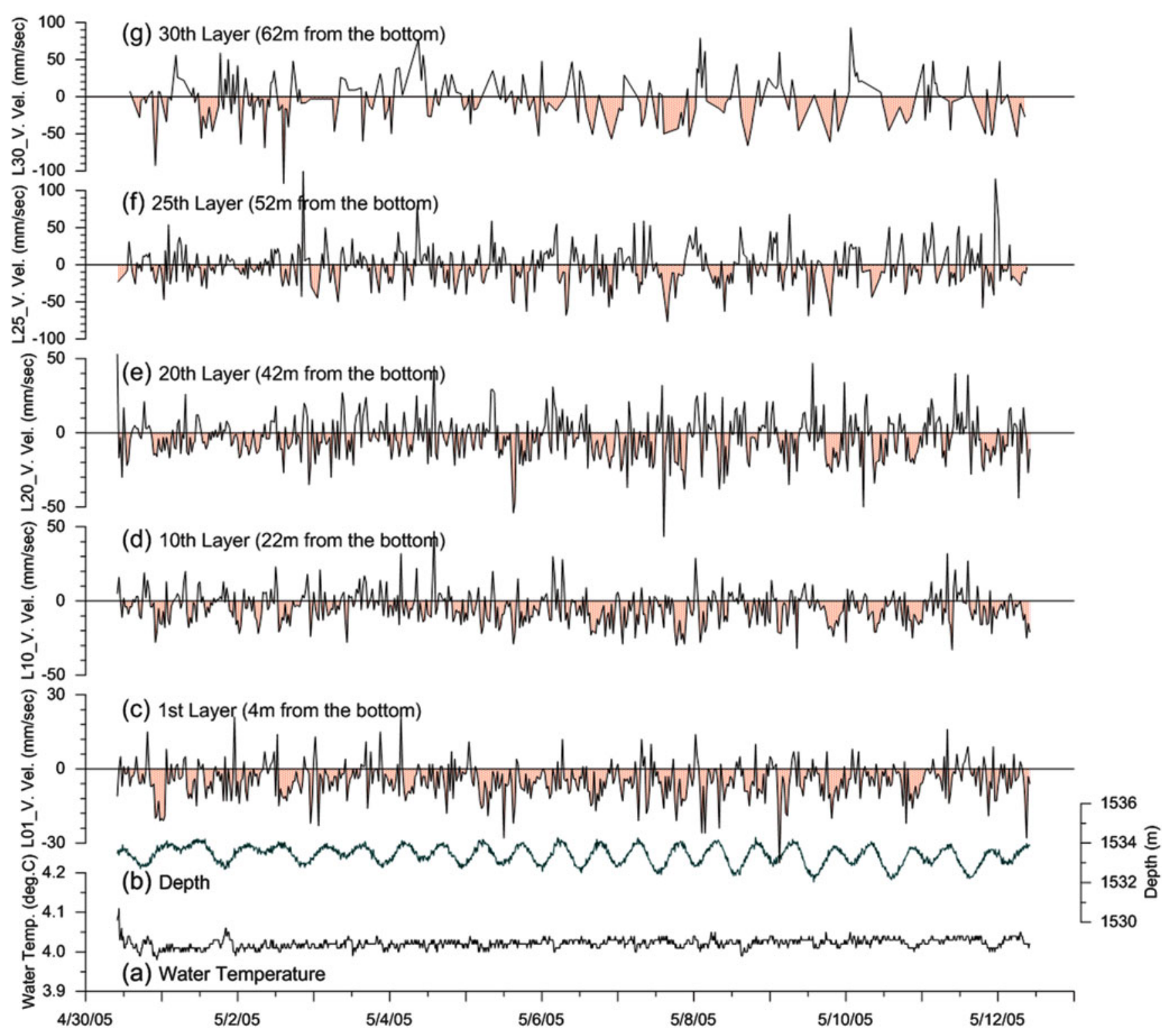

Fig. 50.5 Fluctuation of vertical current velocity, water temperature and depth around the sea bottom. (a) Water Temperature $\left({ }^{\circ} \mathrm{C}\right)$. (b) Depth (m). (c) Fluctuation of the layer 1 (4 $\mathrm{m}$ from the bottom). (d) Fluctuation of layer 10 (22 $\mathrm{m}$ from the bottom). (e) Fluctuation of layer

20 (42 $\mathrm{m}$ from the bottom). (f) Fluctuation of layer 25 (52 $\mathrm{m}$ from the bottom). (g) Fluctuation of layer 30 (62 m from the bottom). Current velocity unit is $\mathrm{mm} / \mathrm{s}$. The red hatching in the figure shows the downward current velocity

the movement of the water mass including many particles. Therefore, the distribution of the high backscattering indicates that drifters or marine snow sank down from the upper layer into the lower layer using a clockwise circulation (Figs. 50.9 and 50.10). It is likely that a current measurement would have been impossible because the seawater was extremely clear with low turbidity for $60 \mathrm{~m}$ in the upper layer, except during the time zone when the pulsatile current measurement was confirmed. Measurement of ADCP in venting site would be effective to determine the deep-sea current up to $120-\mathrm{m}$ above the seafloor and to observe behavior of hydrothermal plume if behavior of the high backscattering depends on hydrothermal water effect.

The possible reason for the distribution of high backscattering appearing in a pulse form was considered. Furushima et al. (2009) showed that volume of bubble spout from a geyser of $10 \mathrm{~m}$ water-depth seafloor on the Taketomi submarine hot spring site where is a shallowest hydrothermal vent in eastern Taketomi Island within the Yaeyama archipelago, Japan, was related to tidal periodicity. Furushima et al. (2009) and Nagao et al. (2011) also indicated that the increased upward flux from the Taketomi geyser shifted to a 
Fig. 50.6 Power spectrum of the East-west (dashed line) and the North-south (solid line) components of the velocity in layers 1 and 20
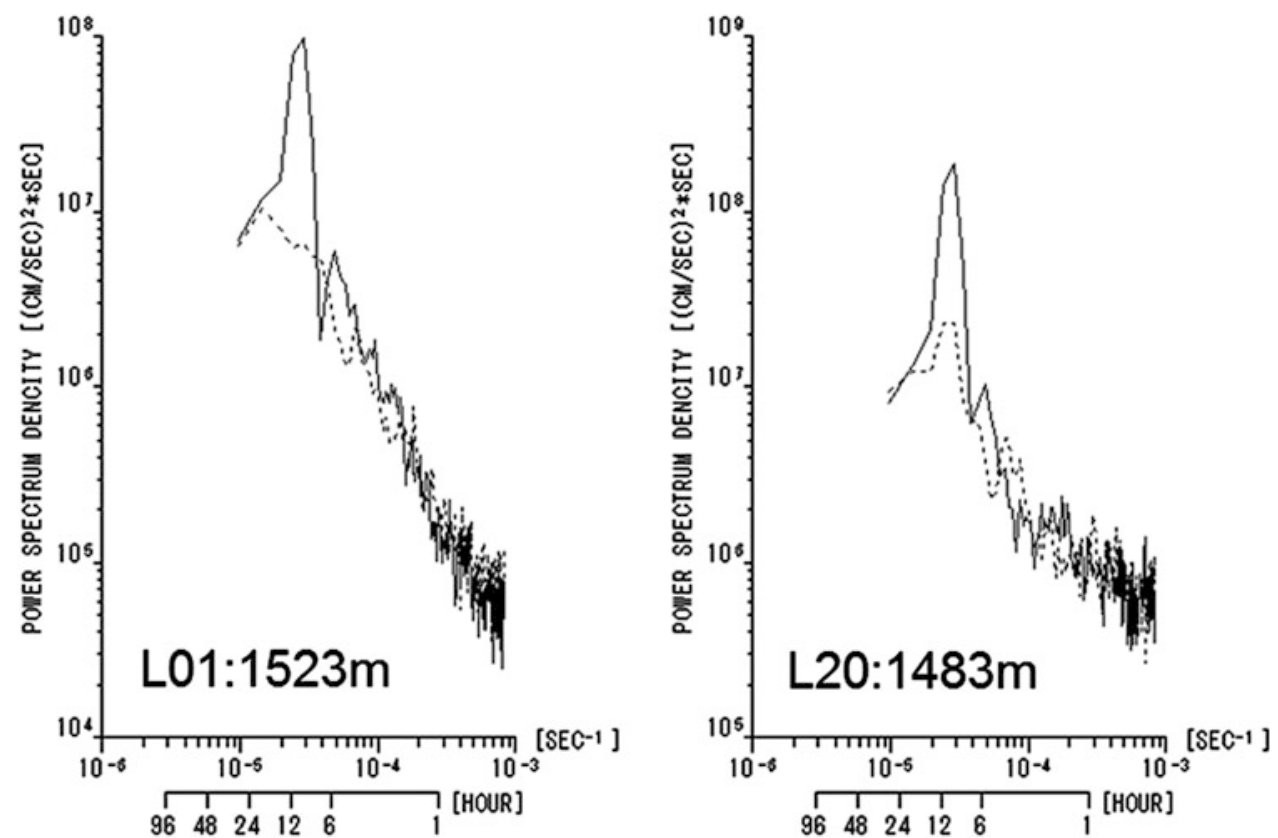

flood tide from an ebb tide period. Additionally Oomori (1987) suggested that the Taketomi submarine hot spring originated in the hydrothermal activity underneath the geological structure of Ryukyu archipelago rather than back-arc system. The distribution of high backscattering was found at a time period in the Hatoma Knoll, when shift to a flood tide from an ebb tide (Fig. 50.10). If the hydrothermal system in the Hatoma knoll was affected by the tidal fluctuation same as the Taketomi submarine hot spring, hydrothermal plume upward flux may increase to a flood tide from an ebb tide period. The three-dimensional mapping of the hydrothermal system and verification by the numerical model may be necessary to understand the distribution of high backscattering appearing in a pulse form.

We finally considered the methods to measure the amount of hydrothermal fluids spouting from the many hydrothermal vents in the caldera at Hatoma Knoll. At sites where the bottom topography is flat and hydrothermal water spouts out from the seabed, a current meter emitting an ultrasonic sound horizontally (e.g. DW-Aquadopp, Nortek AS) can be set up on the bottom, and fluctuation of the vertical flow, flux, and variation of fluid flux, can be determined. However, at Hatoma Knoll, hydrothermal fluid vents from a chimney, and some of the chimneys are more than $10 \mathrm{~m}$ tall. In addition, the bottom topography of vent filed is very complex, and this makes difficulty of bottom installation-type current measurement. Camilli et al. (2011) showed that in the case of the Deepwater Horizon collapsed at Macondo, three-dimensional imaging method by ADCP and acoustic imaging sonar installed to ROV successfully determined the oil leakage on the wellhead. If this measurement technique could apply to hydrothermal field, it make an quantitative determination method to estimate hydrothermal fluid flux from chimney, and provide the information to investigate the physicochemical influence for the marine ecosystem. 


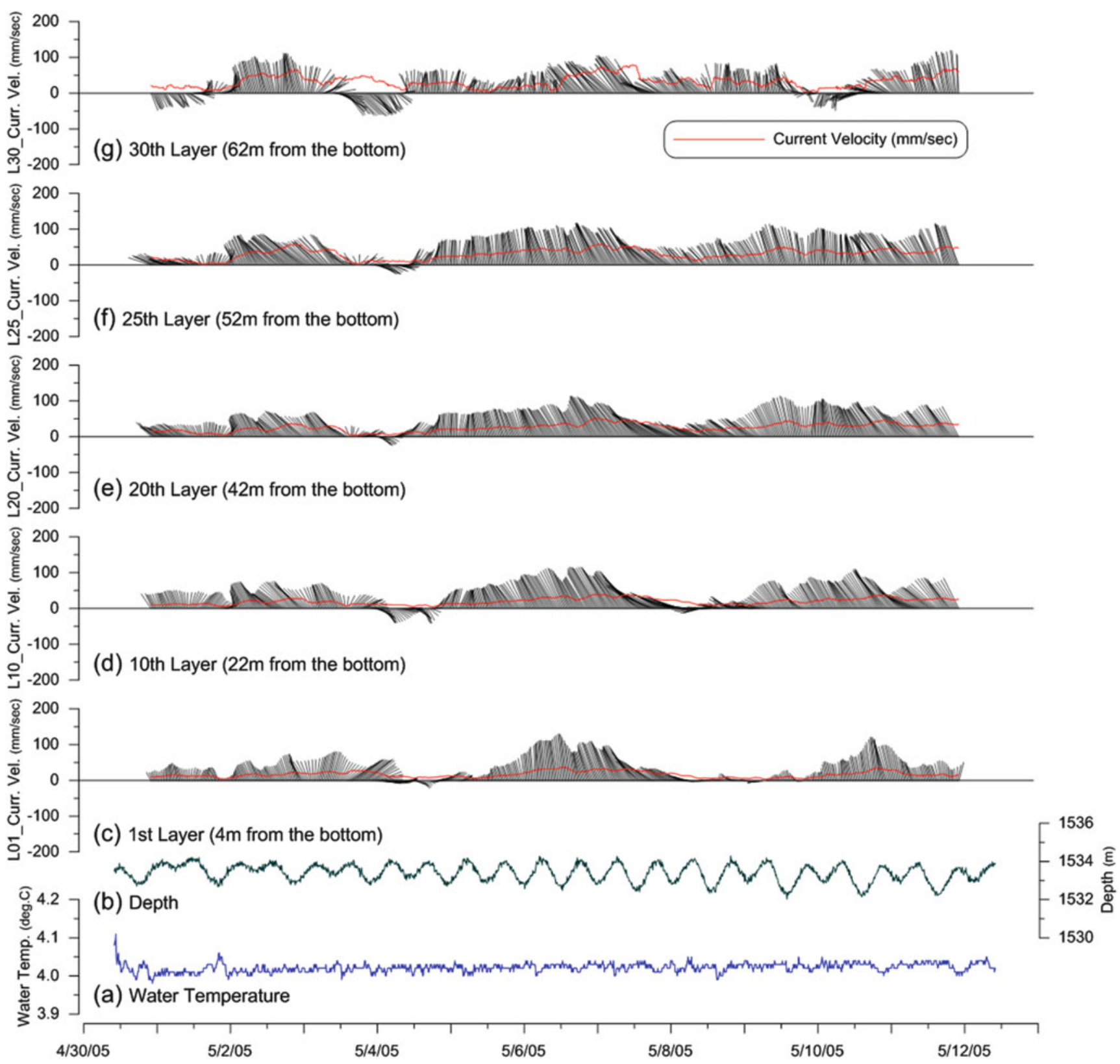

Fig. 50.7 Fluctuation of water temperature and water pressure around the sea bottom. Horizontal current fluctuations with moving average for $25 \mathrm{~h}$ calculated in each layer (from the sea bottom to upper layer at $62 \mathrm{~m})$. (a) Water Temperature $\left({ }^{\circ} \mathrm{C}\right)$. (b) Depth $(\mathrm{m})$ : water pressure. (c) Fluctuation of the current velocity at layer 1 ( $4 \mathrm{~m}$ from the bottom). (d) Fluctuation of the current velocity at layer 10 (22 $\mathrm{m}$ from the bottom).

(e) Fluctuation of the current velocity at layer $20(42 \mathrm{~m}$ from the

bottom). (f) Fluctuation of the current velocity at layer 25 (52 m from the bottom). (g) Fluctuation of the current velocity at layer $30(62 \mathrm{~m}$ from the bottom). The red line shows the current velocity. The black line shows fluctuation of the current velocity and direction. The plus value of the current velocity expresses the northward and eastward flow, respectively. In the case of a negative value, the current velocity represents a southward and westward flow 


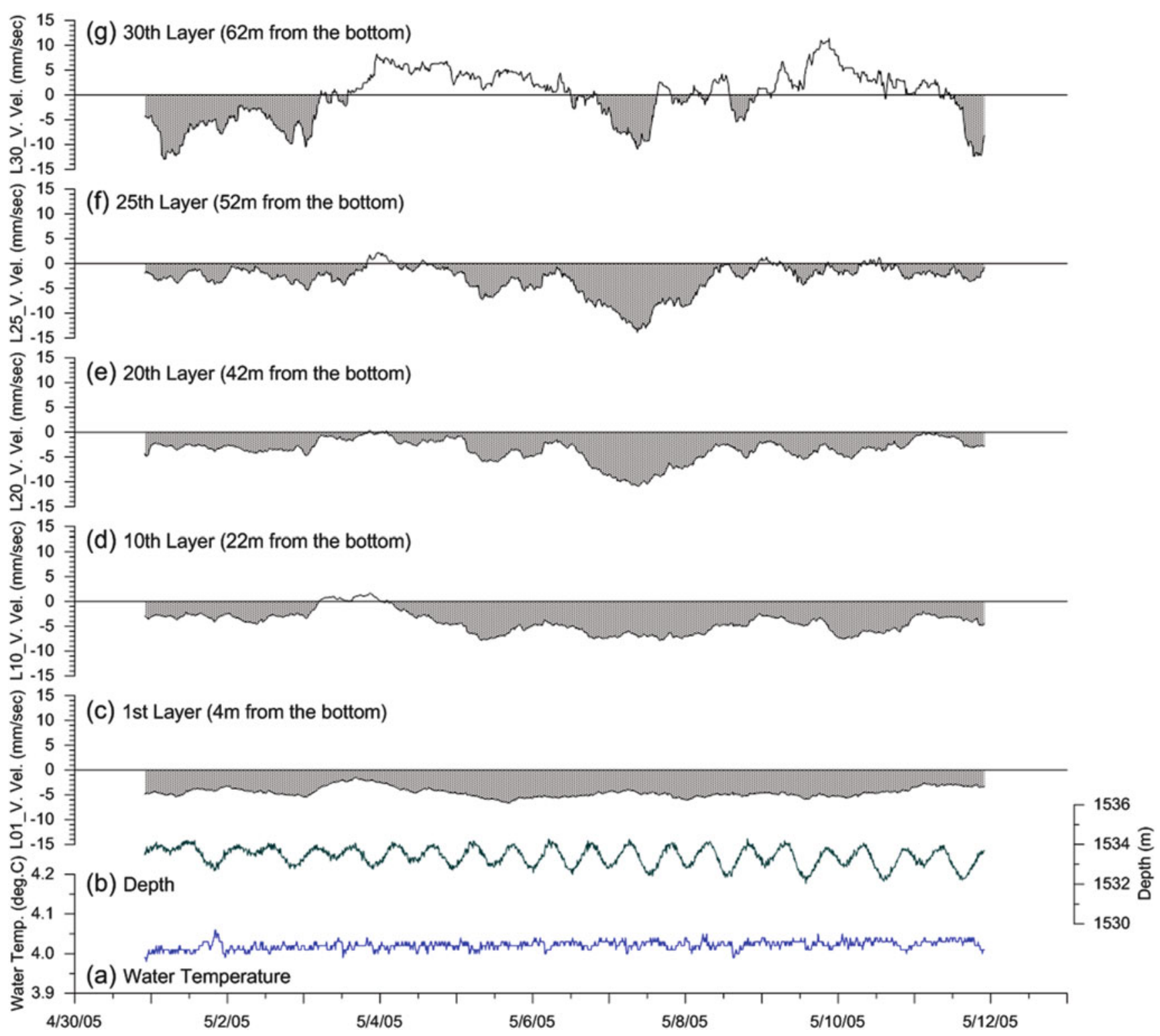

Fig. 50.8 The vertical velocity fluctuation (calculated moving average for $25 \mathrm{~h}$ ) in each layer; and fluctuation of water temperature and depth. (a) Water Temperature $\left({ }^{\circ} \mathrm{C}\right)$. (b) Depth $(\mathrm{m})$. (c) Fluctuation of the vertical current velocity at layer 1 ( $4 \mathrm{~m}$ from the bottom). (d) Fluctuation of the vertical current velocity at layer 10 (22 $\mathrm{m}$ from the bottom). (e) Fluctuation of the vertical current velocity at layer 20 (42 m from

the bottom). (f) Fluctuation of the vertical current velocity at layer 25 (52 $\mathrm{m}$ from the bottom) (g) Fluctuation of the vertical current velocity at layer 30 (62 $\mathrm{m}$ from the bottom). The hatching shows the downward current velocity. The plus value of the current velocity indicates the upward current velocity, and the negative value indicates the downward current velocity 

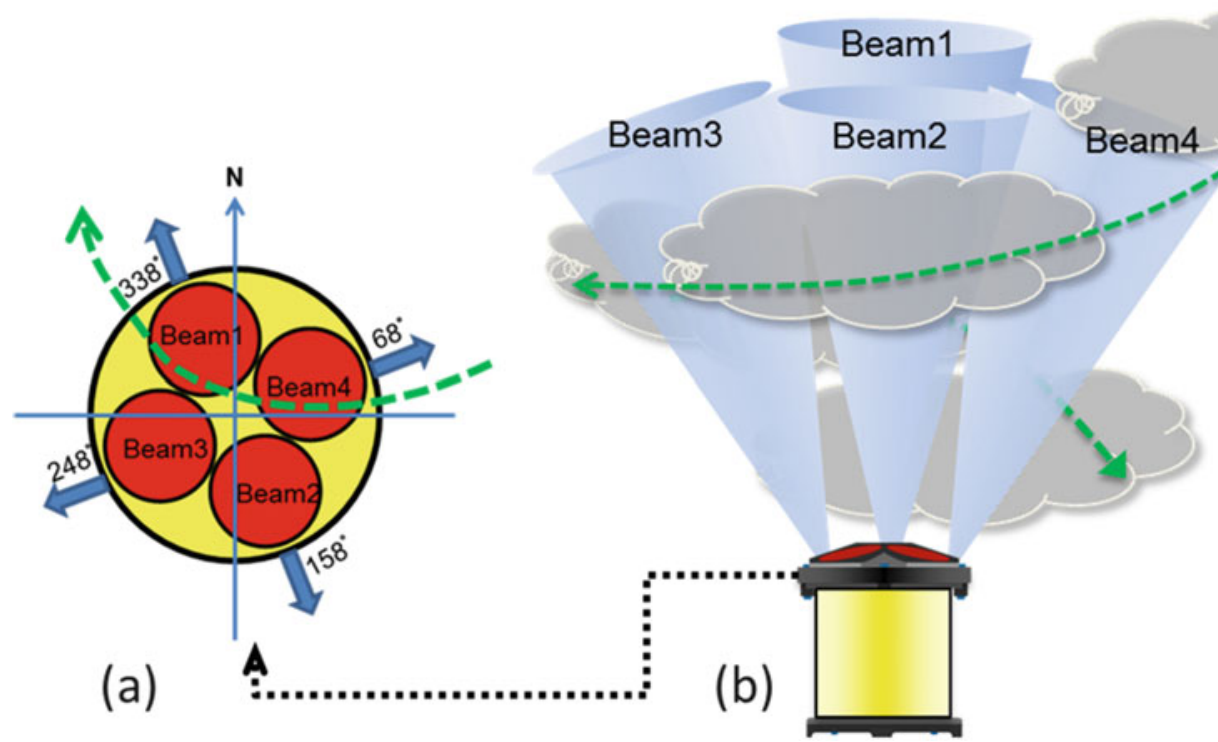

Fig. 50.9 Schematic view of (a) the upper ADCP and direction of the transducers, and (b) movement of a high backscatter. The dotted line arrow indicates that a high backscatter propagates (sink down from the upper layer to lower layer) clockwise 


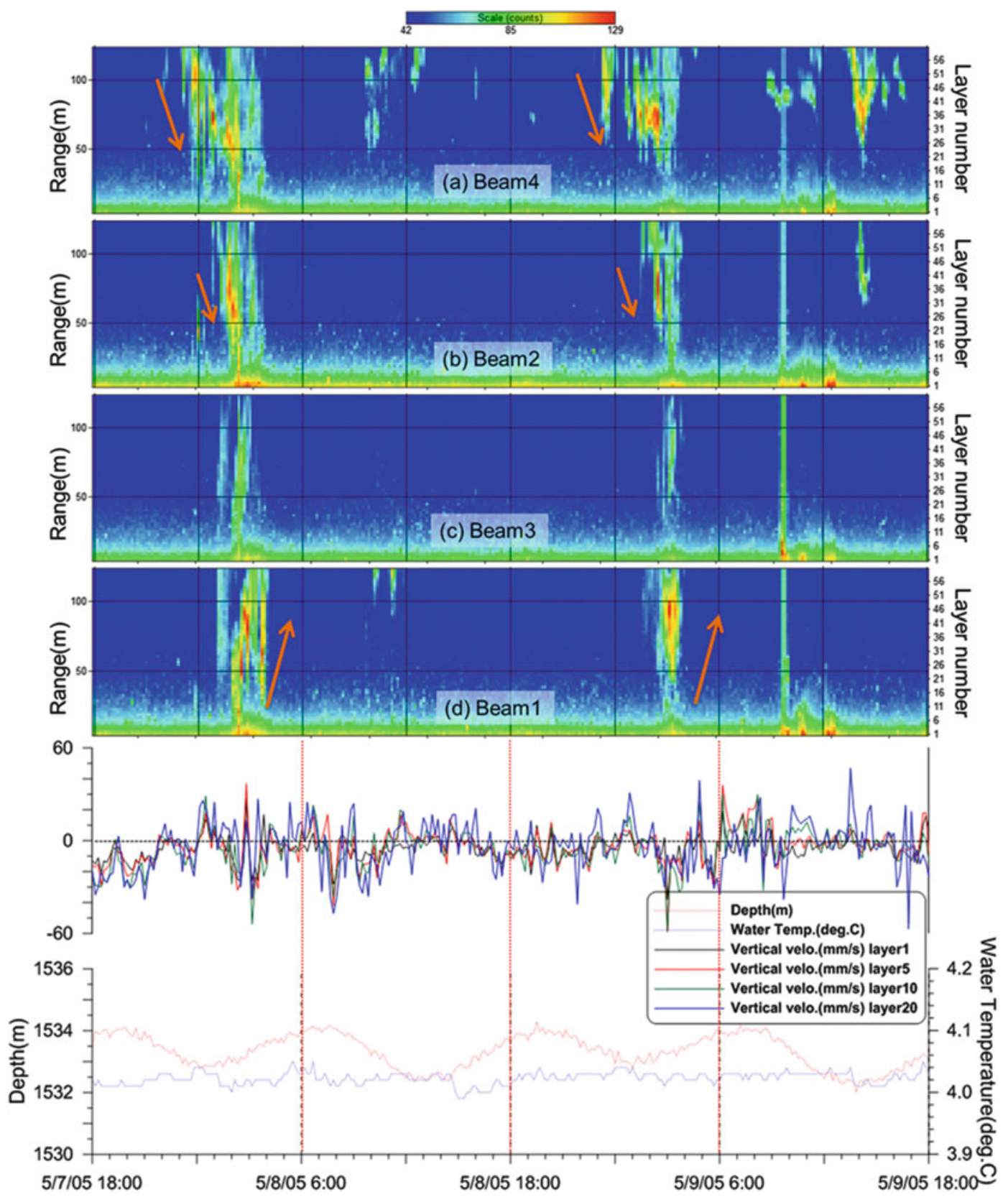

Fig. 50.10 Intensity variation of back scatter signals by ADCP in 2005. The right axis shows the layer number. The left-sided axis shows the height from the approximate sea bottom. Each thickness was set to a $3 \mathrm{~m}$ - resolution and the 50 layers were measured from

Acknowledgements We thank the captain and crew of $\mathrm{R} / \mathrm{V}$ Natsushima and the deep-sea submersible operation teams of HYPER-DOLPHIN 3000 for supporting the observation and for the installation and recovery of the ADCP. We would like to thank the Ministry of Education, Culture, Sports, Science, and Technology (MEXT), Grant-in-Aid for Scientific Research on Innovative Areas TAIGA (20109003), for its partial support for this research.

Open Access This chapter is distributed under the terms of the Creative Commons Attribution Noncommercial License, which permits any the seafloor. (a) Backscatter signal intensity of Beam 4, (b) backscatter signal intensity of Beam 2, (c) backscatter signal intensity of Beam 3, (d) backscatter signal intensity of Beam 1

noncommercial use, distribution, and reproduction in any medium, provided the original author(s) and source are credited.

\section{References}

Aucan J, Merrifield MA, Luther DS, Flament P (2006) Tidal mixing event on the deep flanks of Kaena ridge, Hawaii. J Phys Oceanogr 36:1202-1219 
Baker ET, Cormier M-H, Langmuir CH, Zavala K (2001) Hydrothermal plumes along segments of contrasting magmatic influence, $15^{\circ} 20^{\prime}-18^{\circ} 30^{\prime} \mathrm{N}$, East Pacific Rise: influence of axial faulting. Electr J Earth Sci 2:2000GC000165

Camilli R, Di Iorio D, Bowen A, Reddy CM, Techet AH, Yoerger DR, Whitcomb LL, Seewald JS, Sylva SP, Fenwick J (2011) Acoustic measurement of the deepwater horizon Macondo well flow rate. Proc Natl Acad Sci U S A 1100385108:1-5

Emery WJ, Thomson RE (2004) Data analysis methods in physical oceanography, 2nd edn. Elsevier, New York

Fujioka K, Mitsuzawa K (2001) Tide-related variability of hydrothermal activity at the TAG hydrothermal mound, mid-Atlantic Ridge and the East Pacific Rise. J Geodetic Soc Jpn 47(1):434-440

Fujioka K, Kobayashi K, Kato K, Aoki M, Mitsuzawa K, Kinoshita M, Nishizawa A (1997) Tide-related variability of TAG hydrothermal activity observed by deep-sea monitoring system and OBSH. Earth Planet Sci Lett 153:239-250

Furushima Y, Nagao M, Suzuki A, Yamamoto H, Maruyama T (2009) Periodic behavior of the bubble jet (Geyser) in the Taketomi submarine hot springs of the southern part of Yaeyama Archipelago. Jpn Mar Technol Soc J 43:13-22
Mitsuzawa K (2003) The application of ADCP to the measurement of current system at the hydrothermal active areas. In: Proceedings of the IEEE/OES seventh conference on current measurement technology, pp 246-249

Nagao M, Furushima Y, Suzuki A, Yamamoto H, Maruyama T (2011) Relative bubble density and flux discharged from an underwater geyser varying with tide. Ann J Hydra Eng 55:211-216

Oomori T (1987) Chemical composition of submarine hot spring water and associated bottom sediments near taketomi-jima at southern part of the Ryukyu island arc, north-west pacific. J Earth Sci Nagoya Univ 35(2):325-340

Pond S, Pickard GL (1983) Introductory dynamical oceanography, 2nd edn. Pergamon, New York, pp 253-281

Thomson RE, Miha'ly SF, Rabinovich AB, McDuff RE, Veirs SR, Stahr FR (2003) Constrained circulation at Endeavour ridge facilitates colonization by vent larvae. Nature 424:545-549

Vrijenhoek RC (2010) Genetic diversity and connectivity of deep-sea hydrothermal vent metapopulations. Mol Ecol 19:4391-4411

Watanabe K (2001) Mapping the hydrothermal activity area on the Hatoma Knoll in the southern Okinawa Trough. JAMSTEC J Deep Sea Res 19:87-94 (in Japanese with English abstract) 